\title{
Depression in primary care: assessing suicide risk
}

\author{
Chung Wai Mark $\underline{\mathrm{Ng}}^{1}$, MMed, FCFP, Choon How $\underline{\mathrm{How}}^{2}$, MMed, FCFP, Yin Ping $\underline{\mathrm{Ng}}{ }^{3,4}$, MB BCh BAO, DrPsych
}

Judy, your regular patient, visited your clinic for follow-up of her diabetic condition. Throughout the consultation, you noticed that her head was lowered. She was not her usual cheerful self and avoided eye contact with you. You recalled that she had recently undergone a divorce and had been struggling to get back into the workforce for the past three months. You probed further and found out that she was depressed. You were concerned that she might be suicidal.

\section{HOW RELEVANT IS THIS TO MY PRACTICE?}

Major depression is a risk factor for suicide, accounting for up to $60 \%$ of suicides. ${ }^{(1-4)}$ The literature has shown that a large proportion of patients who died by suicide had made contact with a primary care health provider within the three months preceding their deaths. ${ }^{(5-7)}$ Patients who died by suicide were also more likely to visit their primary care practitioner than a psychiatrist. ${ }^{(6)}$ This suggests that primary care practitioners are in a unique position to identify at-risk individuals and possibly intervene. ${ }^{(6,8,9)}$ Primary care practitioners have been identified as one of the key potential gatekeepers in suicide prevention efforts. ${ }^{(10)}$ Despite this, not all primary care practitioners routinely ask about suicide in depressed patients. ${ }^{(11)}$

\section{WHAT CAN I DO IN MY PRACTICE?}

There are concerns that enquiring about suicide in patients who are depressed may trigger suicide, but evidence has shown this to be untrue. ${ }^{(12)}$ Acknowledging and discussing suicide may reduce, instead of aggravate, suicidal ideation. Asking about suicide may help primary care physicians to identify high-risk patients who require urgent intervention (such as hospitalisation) and to uncover risk factors, some of which are amenable to intervention. ${ }^{(9)}$

There are numerous tools to screen for suicide risk. One of the more widely used suicide assessment tools is the SAD PERSONS scale. This is a ten-item mnemonic, which was first developed as a tool for medical students and non-psychiatrist physicians to guide suicide risk assessment. ${ }^{(13)}$ The use of the tool has been found to improve identification of persons with suicidal ideation. ${ }^{(14)}$ The letters in the mnemonic represent demographic, behavioural and psychosocial risk factors for suicide (Box 1). Each risk factor that is present is accorded a score of 1 point, for a maximum of 10 points. Patterson et al recommended that: (a) patients with scores of 3-4 should be closely monitored; (b) hospitalisation should be strongly considered for those with

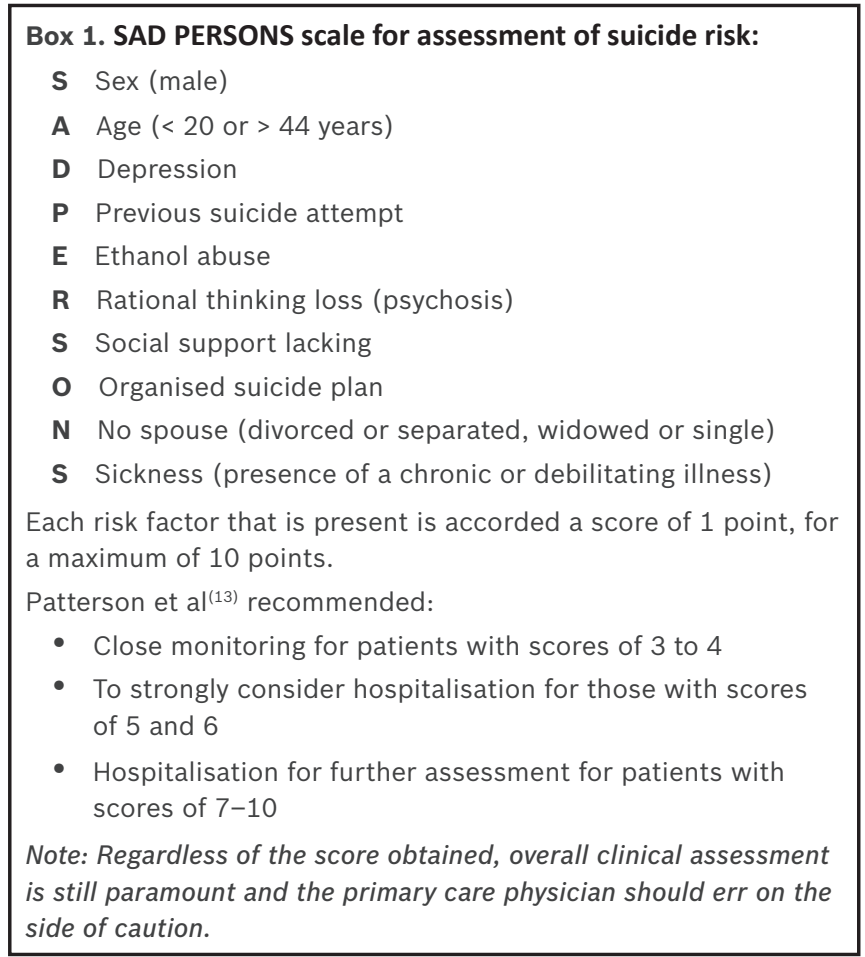

scores of 5 and 6 ; and (c) patients with scores of 7-10 should be hospitalised for further assessment. ${ }^{(13)} A$ systematic review of the performance of the SAD PERSONS scale in the clinical setting concluded that it did not acutely predict suicide behaviour. ${ }^{(15)}$ Nonetheless, it is an easy scale to remember and use in the primary care setting.

Information acquired via such assessment tools can add to the overall information obtained during a thorough suicide assessment. However, a systematic review concluded that there was insufficient evidence for the usefulness of suicide risk screening tools and that suicide assessment tools should not replace a thorough suicide assessment. ${ }^{(16)}$ According to the recommendations of the Royal College of Psychiatrists, suicide

\footnotetext{
${ }^{1}$ SingHealth Polyclinics, ${ }^{2}$ Care and Health Integration, Changi General Hospital, Singapore, ${ }^{3}$ Penang Medical College, ${ }^{4}$ Penang Adventist Hospital, Penang, Malaysia Correspondence: Dr Ng Chung Wai Mark, Senior Consultant and Family Physician, SingHealth Polyclinics - Outram, Health Promotion Board Building Level 2, 3 Second Hospital Avenue, Singapore 168937. ng.chung.wai@singhealth.com.sg
} 
risk assessment tools "should be seen as part of routine assessment and not as a separate exercise ${ }^{\prime \prime}{ }^{(17)}$

Evaluation should be customised and performed in a manner that is sensitive to the patient's culture and religion. It should also take into consideration any risk factors and warning signs. Clinical judgement is important, and the clinician should err on the side of caution. Thorough documentation and communication of details is important to ensure adequate monitoring and the safety of the person. ${ }^{(18)}$ Assessing the patient's suicide risk involves: (a) checking for known risk factors of suicide; (b) eliciting suicidal ideation from the patient (or corroborative sources); and (c) deciding if the patient is at imminent risk of suicide, based on the patient's current ideation and existing risk factors. ${ }^{(19)}$

\section{Checking for suicide risk factors}

Some of the risk factors for suicide are amenable to intervention, whereas others are not. A large prospective study identified hopelessness, higher levels of suicidal ideation, recurrent episodes of depression, presence of personality disorders, previous psychiatric hospitalisation, older age, unemployed status and a family history of suicide as significant markers for suicide. ${ }^{(20)}$ Having one or more previous suicide attempts is a very strong predictor of suicide risk. ${ }^{(21)}$ Having pervasive thoughts of hopelessness has also been identified as a very important risk factor. ${ }^{(22,23)}$ Additional risk factors include the presence of other psychiatric comorbidities such as anxiety disorders and substance misuse, ${ }^{(10,24)}$ chronic physical illnesses, ${ }^{(25)}$ a recent stressful life event, ${ }^{(26)}$ and social isolation, ${ }^{(27)}$ which includes living alone, coming from a broken family, divorce and spousal bereavement. Access to lethal means is another risk factor; the most common mode of suicide in Singapore is jumping from heights, followed by hanging and poisoning. ${ }^{(28)}$ The risk factors for suicide are summarised in Box 2 .

In contrast to risk factors, protective factors lower the risk of suicide. Therefore, apart from strategies to reduce the risk factors for suicide, interventions should aim to strengthen factors that protect against suicide. These include strong interpersonal relationships, religious faith, positive coping strategies such as effective stress management and healthy lifestyle choices, including diet and exercise. ${ }^{(10,29)}$

\section{Eliciting suicidal ideation}

There are no fixed methods to elicit suicidal ideation. Some patients may inform the doctor without the need for prompting, while others may view it with shame. Therefore, it is prudent to raise the topic carefully in a sensitive and respectful manner, by first using open-ended questions and gradually focusing on direct ones. It may be easier to broach the subject while exploring mood symptoms or discussing negative feelings. One should be mindful not to overreact even if there is a cause for concern. ${ }^{(30)}$ Important components of suicidal ideation that should be explored are listed in Box 3. (31-33) $^{-1}$

A step-wise approach (Fig. 1) has been suggested by several authors, ${ }^{(19,24,34)}$ in which the primary care practitioner starts off by asking a general question on whether the patient has ever
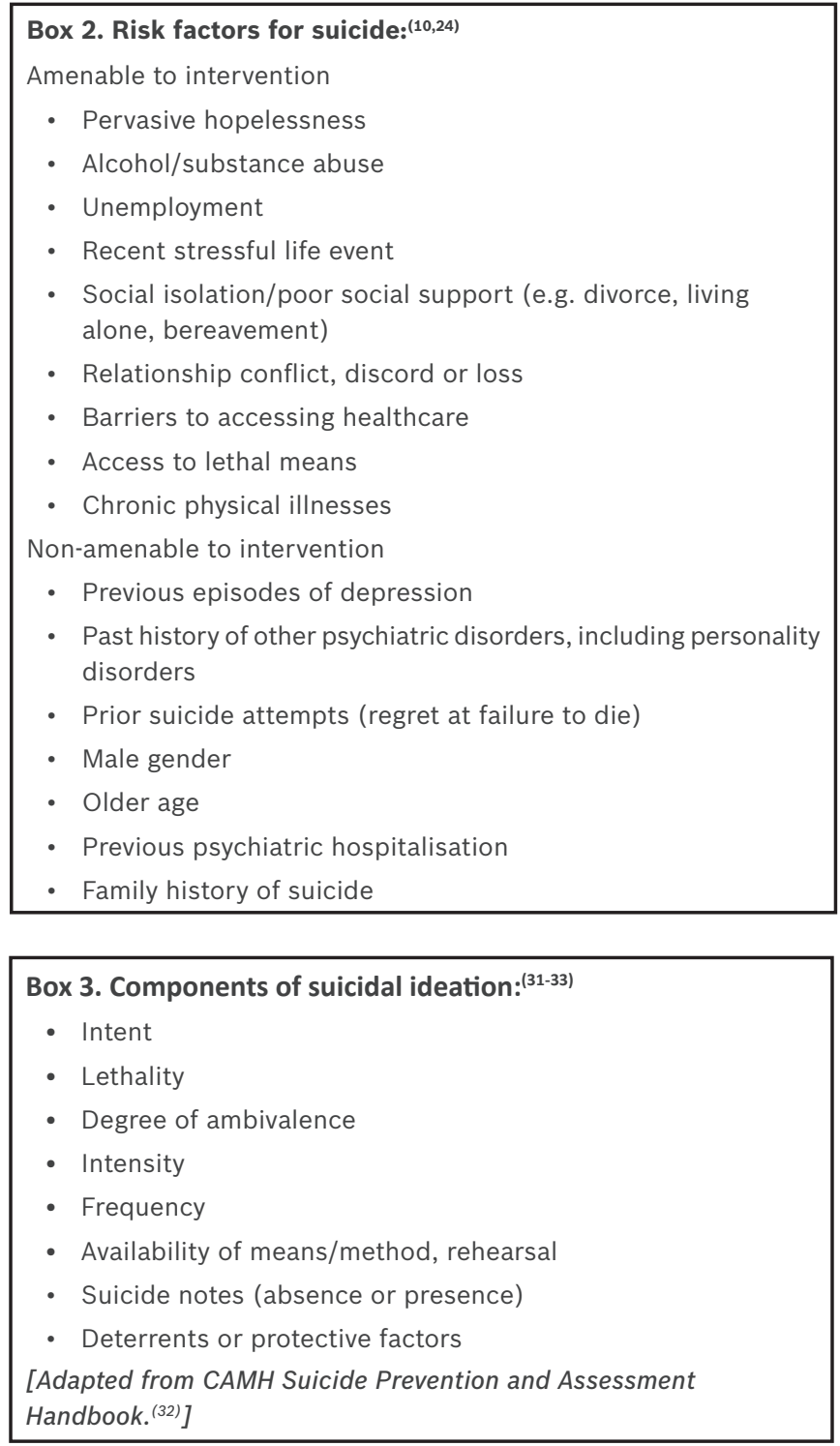

had any thoughts of death or felt that he or she is better off dead. A positive response to this question should prompt the next question - whether the patient has any thoughts of self-harm. If there are no thoughts of self-harm, the patient is said to have passive suicidal ideation. The primary care practitioner should then explore and mitigate any additional risk factors for suicide, and help the patient get in touch with relevant community resources, such as crisis helplines. With the patient's permission, the patient's risk can be made known to a family member or close friend.

Conversely, if thoughts of self-harm are present, the patient is said to have active suicidal ideation and should be given a same-day psychiatric assessment. The primary care physician should ask further questions to look for behaviour that suggests intent (e.g. making a suicide note or distributing personal belongings), or whether there is a specific plan to carry it out. Any patient who communicates a specific intent or plan for suicide requires urgent psychiatric referral and should be transported to the emergency room. ${ }^{(24)}$ Finally, the risk assessment should be documented as clearly and as thoroughly as possible to 


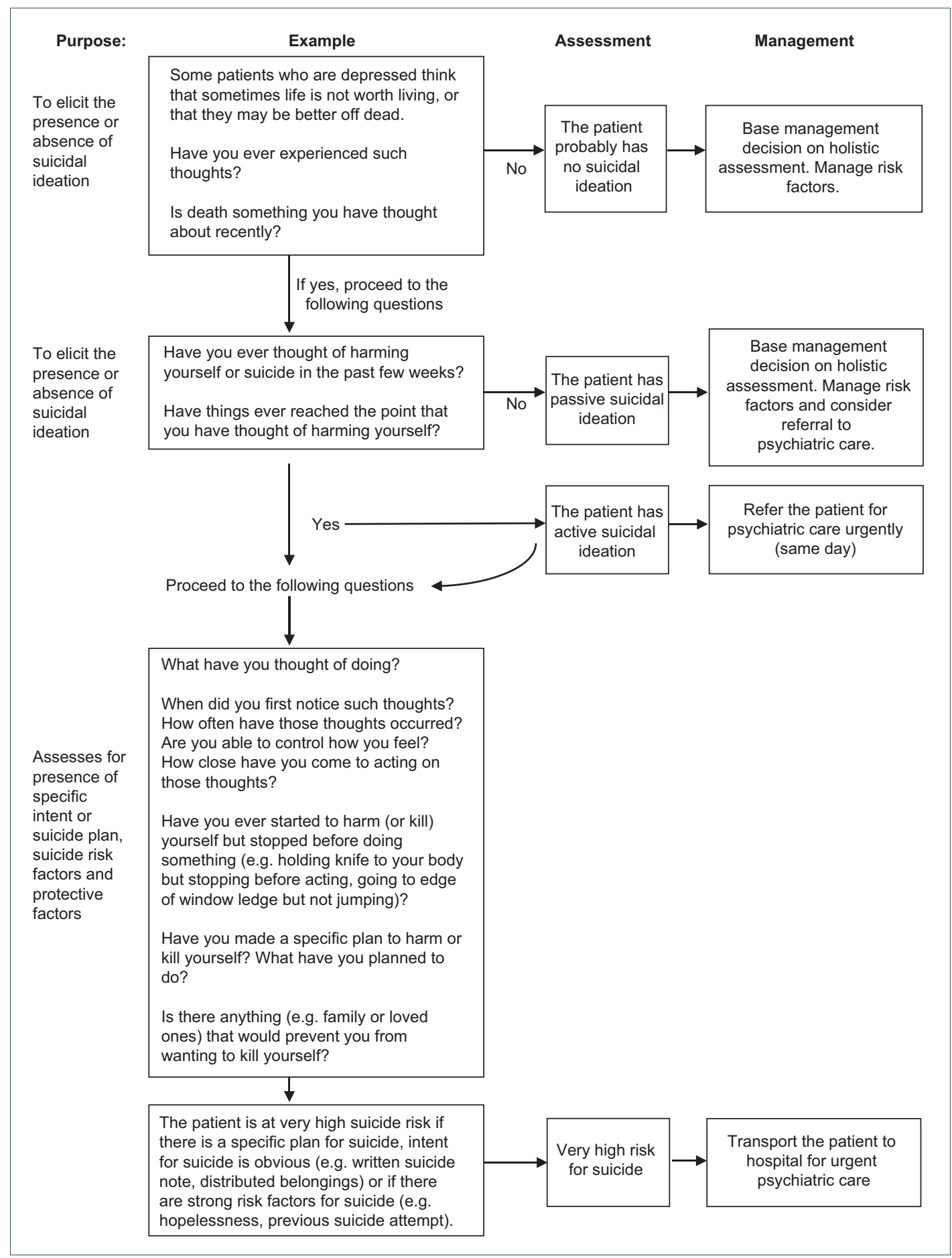

Fig. 1 Step-wise approach to assessing suicidal ideation.

facilitate communication between healthcare providers, ongoing assessment and continuity of care.

\section{Cultural aspects relevant to Asia}

In Asian society, one may encounter patients who quickly deny or brush off thoughts of suicide due to the fear of stigma or judgement, or because their religious faith forbids them from entertaining such thoughts. Although religious faiths may seem protective, the fear of judgement about harbouring such ideas may serve as a barrier to reporting of suicidal ideation. ${ }^{(35)}$ In such patients, it may be helpful to broach the topic in a gentle, sensitive and normalising manner. This is an example of what one might say to such patients: "This may be a sensitive topic in some religions, but when people are very unhappy or overwhelmed by sadness, they can sometimes experience thoughts that life is not worth living. These thoughts come automatically and are not always controllable. Have you ever experienced anything like this?"

\section{Managing patients with suicide risk}

Suicide risk assessment is a complex and challenging process that relies on effective communication, and it is an ongoing process for the depressed patient. ${ }^{(18)}$ Therefore, a holistic approach should be 
employed. Primary care physicians should base decision-making on clinical judgement and not rely solely on the cut-off scores of the suicidal ideation assessment tool.

The main challenge for the primary care physician is deciding whether the patient should be managed at primary care or referred for tertiary psychiatric care (and the urgency of the latter). All persons with clear-cut active suicidal ideation should be sent to the designated hospital (i.e. Institute of Mental Health in the Singapore context) for urgent psychiatric care. However, when it comes to managing cases that are less clear-cut - such as a patient with passive suicidal ideation following a recent stressor, who has poor support, a past history of self-harm and poor coping skills - decision-making can be difficult. The physician may still decide to send such patients for urgent assessment if the patient is deemed unsafe.

Another potential dilemma that may arise is the issue of confidentiality. Patients may not consent to the doctor informing their family members about their suicide risk. In such cases, if the patient is at imminent risk, the concerns of safety override the considerations of confidentiality. ${ }^{(4,31)}$ However, it is prudent to inform the patient that, in the event of safety concerns, the doctor may be obligated to disclose the patient's suicide risk to the family or relevant persons for his or her best interests.

\section{Optimising treatment of underlying depressive disorder}

For all depressed patients, the management of their underlying depressive disorder, which includes both pharmacological and psychological therapies, should be optimised; antidepressants should be commenced in patients who are not on any medication. Our previous article illustrated the approach to diagnosis of major depression in primary care. ${ }^{(36)}$ The physician should make an effort to look out for any comorbid illnesses, such as chronic physical illnesses, anxiety, substance misuse or personality disorders, which may complicate management. To prevent harmful overdosing, adherence to medication should be checked and strictly supervised, if deemed necessary.

\section{Information to be provided upon transfer}

In cases where the patient is required to be transferred for urgent psychiatric care, salient information should be provided to facilitate continuity of care. This includes information on the level of suicide risk and the reason for it, pertinent demographic data, risk factors, mental state examination results, past medical history, medication, treatment plans and social contacts.

\section{Safety plans}

Safety plans should be discussed and developed with depressed patients who are at risk of suicide. This usually involves recognising signs of impending suicidal crisis (such as specific triggers or suicidal thoughts), planning coping methods in advance to deal with future suicidal urges, and identifying individuals or agencies (with their respective contact details) that the patient can contact to facilitate patient safety and lower the risk of imminent suicidal behaviour. ${ }^{(32,37)}$ If there is already an existing safety plan, the primary care physician should actively discuss it with the patient, and revisit the plan when there is a change in suicide risk level. However, should the doctor or patient feel that the patient is at imminent risk and unable to remain safe, the patient should immediately be sent to the hospital for urgent psychiatric care.

Another intervention that is commonly used is the 'no-suicide contract' or 'no-harm contract'. No-suicide contracts are not the same as safety plans. They involve statements from patients promising not to harm themselves or that they will contact someone in the event that they are unable to maintain their own safety. Although commonly used, the practice of forming nosuicide contracts should be discouraged, as there is no evidence to suggest that such contracts reduce suicide tendencies, but they may instead be used by patients to hide their actual suicidal intent. ${ }^{(32,38)}$

\section{Linking patients to community resources}

All persons who are depressed or suicidal should be connected to available community resources and crisis helplines. ${ }^{(4,31)}$

Three months later, you met Judy again and saw that she was visibly better. She told you that she was regularly seeing the psychiatrist that you had referred her to and was glad to have found a support group in the community. She sincerely thanked you for your concern and for providing a listening ear when she had most needed it.

\section{TAKE HOME MESSAGES}

1. Suicidal patients are more likely to see a primary care physician than a psychiatrist in the months preceding their death. Primary care physicians are therefore in a unique position to identify at-risk individuals and possibly intervene.

2. Acknowledging and discussing suicide may help to reduce suicidal ideation and identify high-risk patients who require urgent intervention.

3. There are numerous tools available to screen for suicide risk, such as the SAD PERSONS scale. The information acquired can add to the overall information obtained during a thorough suicide assessment.

4. Some suicidal risk factors are amenable to intervention, whereas some are not.

5. Apart from strategies to reduce the risk factors for suicide, interventions should also aim to strengthen the protective factors.

6. Eliciting suicidal ideation requires a step-wise approach, by first using open-ended questions and gradually focusing on direct ones.

7. All persons with clear-cut, active suicidal ideation should be sent to the designated hospital for urgent psychiatric care.

8. Safety plans should be discussed and developed with all patients who are at risk of suicide.

9. Depressed or suicidal patients should be connected to available community resources. 
ABSTRACT Major depression is a common condition seen in the primary care setting. This article describes the suicide risk assessment of a depressed patient, including practical aspects of history-taking, consideration of factors in deciding if a patient requires immediate transfer for inpatient care and measures to be taken if the patient is not hospitalised. It follows on our earlier article about the approach to management of depression in primary care.

Keywords: depression, primary care, suicide risk assessment

\section{REFERENCES}

1. Gaynes BN, West SL, Ford CA, et al. Screening for suicide risk in adults: a summary of the evidence for the U.S. Preventive Services Task Force. Ann Intern Med 2004; 140:822-35.

2. Stoudemire A, Frank R, Hedemark N, Kamlet M, Blazer D. The economic burden of depression. Gen Hosp Psychiatry 1986; 8:387-94.

3. Angst J, Angst F, Stassen HH. Suicide risk in patients with major depressive disorder. J Clin Psychiatry 1999; 60 Suppl 2:57-62; discussion 75-6, 113-6.

4. Reeves A. Working with Risk in Counselling and Psychotherapy. SAGE Publications Limited, 2015.

5. De Leo D, Draper BM, Snowdon J, Kõlves K. Contacts with health professionals before suicide: missed opportunities for prevention? Compr Psychiatry 2013; 54:1117-23.

6. Luoma JB, Martin CE, Pearson JL. Contact with mental health and primary care providers before suicide: a review of the evidence. Am J Psychiatry 2002; 159:909-16.

7. Pearson A, Saini P, Da Cruz D, et al. Primary care contact prior to suicide in individuals with mental illness. Br J Gen Pract 2009; 59:825-32.

8. Andersen UA, Andersen M, Rosholm JU, Gram LF. Contacts to the health care system prior to suicide: a comprehensive analysis using registers for general and psychiatric hospital admissions, contacts to general practitioners and practising specialists and drug prescriptions. Acta Psychiatr Scand 2000; 102:126-34.

9. Pfaff JJ, Acres JG, McKelvey RS. Training general practitioners to recognise and respond to psychological distress and suicidal ideation in young people. Med J Aust 2001; 174:222-6.

10. World Health Organization. Preventing suicide: a global imperative: WHO [online]. Available at: http://www.who.int/mental_health/suicideprevention/world_report_2014/en/. Accessed January 12, 2017.

11. Feldman MD, Franks $P$, Duberstein PR, et al. Let's not talk about it: suicide inquiry in primary care. Ann Fam Med 2007; 5:412-8.

12. Dazzi T, Gribble R, Wessely S, Fear NT. Does asking about suicide and related behaviours induce suicidal ideation? What is the evidence? Psychol Med 2014; 44:3361-3.

13. Patterson WM, Dohn HH, Bird J, Patterson GA. Evaluation of suicidal patients: the SAD PERSONS scale. Psychosomatics 1983; 24:343-5, 348-9.

14. Juhnke GA, Hovestadt AJ. Using the SAD PERSONS scale to promote supervisee suicide assessment knowledge. Clin Superv 1995; 13:31-40.

15. Warden S, Spiwak R, Sareen J, Bolton JM. The SAD PERSONS scale for suicide risk assessment: a systematic review. Arch Suicide Res 2014; 18:313-26.

16. O'Connor E, Gaynes B, Burda BU, Williams C, Whitlock EP; US Preventive Services Task Force Evidence Syntheses, formerly Systematic Evidence Reviews. Screening for suicide risk in primary care: a systematic evidence review for the US Preventive Services Task Force. Rockville (MD): Agency for Healthcare Research and Quality (US); 2013 Apr. Report No.: 1305188-EF-1.
17. Royal College of Psychiatrists. CR158. Self-Harm, Suicide and Risk: Helping People Who Self-Harm [online]. Available at: http://www.rcpsych.ac.uk/ files/pdfversion/CR158xx.pdf. Accessed January 12, 2017.

18. Granello DH. The process of suicide risk assessment: twelve core principles. J Couns Dev 2010; 88:363-70.

19. Shea SC. The chronological assessment of suicide events: a practical interviewing strategy for the elicitation of suicidal ideation. J Clin Psychiatry 1998; 59 Suppl 20:58-72.

20. Brown GK, Beck AT, Steer RA, Grisham JR. Risk factors for suicide in psychiatric outpatients: a 20-year prospective study. J Consult Clin Psychol 2000; 68:371-7.

21. Haney EM, O'Neil ME, Carson S, et al. Suicide Risk Factors and Risk Assessment Tools: A Systematic Review. Washington (DC): Department of Veterans Affairs; 2012.

22. Young MA, Fogg LF, Scheftner W, et al. Stable trait components of hopelessness: baseline and sensitivity to depression. J Abnorm Psychol 1996; 105:155-65.

23. Dahlsgaard KK, Beck AT, Brown GK. Inadequate response to therapy as a predictor of suicide. Suicide Life Threat Behav 1998; 28:197-204.

24. Raue PJ, Ghesquiere AR, Bruce ML. Suicide risk in primary care: identification and management in older adults. Curr Psychiatry Rep 2014; 16:466.

25. Scott KM, Hwang I, Chiu WT, et al. Chronic physical conditions and their association with first onset of suicidal behavior in the world mental health surveys. Psychosom Med 2010; 72:712-9.

26. Overholser JC, Braden A, Dieter L. Understanding suicide risk: identification of high-risk groups during high-risk times. J Clin Psychol 2012; 68:349-61.

27. Van Orden KA, Witte TK, Cukrowicz KC, et al. The interpersonal theory of suicide. Psychol Rev 2010; 117:575-600.

28. Chia BH, Chia A, Ng WY, Tai BC. Suicide methods in singapore (20002004): types and associations. Suicide Life Threat Behav 2011; 41:574-83.

29. Nelson C, Johnston M, Shrivastava A. Improving risk assessment with suicidal patients: a preliminary evaluation of the clinical utility of the Scale for Impact of Suicidality--Management, Assessment and Planning of Care (SIS-MAP). Crisis 2010; 31:231-7.

30. Keith Hawton CC, Kate Saunders, Camilla Haw, et al; University of Oxford's Centre for Suicide Research. Clinical Guide: Assessment of suicide risk in people with depression [online]. Available at: http://cebmh.warne.ox.ac. uk/csr/Clinical_guide_assessing_suicide_risk.pdf. Accessed on January 13, 2017.

31. Samra J, Monk L, White J, Goldner E. Working with the Client Who is Suicidal: A Tool for Adult Mental Health and Addiction Services [online]. Available at: http://www.sfu.ca/content/dam/sfu/carmha/resources/wwcis/ WWCWIS.pdf. Accessed January 13, 2017

32. Centre for Addiction and Mental Health. CAMH Suicide Prevention and Assessment Handbook [online]. Available at: https://www.camh. ca/en/hospital/health_information/a_z_mental_health_and_addiction_ information/suicide/Documents/sp_handbook_final_feb_2011.pdf. Accessed January 13, 2007.

33. Jacobs D, Gutheil T, Harburger J, et al. Guidelines for identification, assessment, and treatment planning for suicidality. Cambridge, MA: Risk Management Foundation of the Harvard Medical Institutions, 1996.

34. McDowell AK, Lineberry TW, Bostwick JM. Practical suicide-risk management for the busy primary care physician. Mayo Clin Proc 2011; 86:792-800.

35. Hendin H, Phillips MR, Vijayakumar L, et al. Suicide and Suicide Prevention in Asia. World Health Organization, 2008.

36. $\mathrm{Ng} \mathrm{CW}$, How $\mathrm{CH}, \mathrm{Ng}$ YP. Major depression in primary care: making the diagnosis. Singapore Med J 2016; 57:591-7.

37. Stanley B, Brown GK. Safety planning intervention: a brief intervention to mitigate suicide risk. Cogn Behav Pract 2012; 19:256-64.

38. Kelly KT, Knudson MP. Are no-suicide contracts effective in preventing suicide in suicidal patients seen by primary care physicians? Arch Fam Med 2000; 9:1119-21. 


\section{SINGAPORE MEDICAL COUNCIL CATEGORY 3B CME PROGRAMME} (Code SMJ 201702A)

1. A large proportion of patients who commit suicide do not make contact with a primary care health provider within the three months preceding their deaths.

2. Patients who die from suicide are more likely to visit their psychiatrist than their primary health care practitioner.

3. There may be opportunities for primary care physicians to identify suicidal patients and possibly intervene.

4. Acknowledging and discussing suicide aggravates suicidal ideation rather than reducing it.

5. Asking about suicide may help the physician to identify a patient at high risk who needs urgent intervention, as well as uncover risk factors for suicide.

6. Some risk factors for suicide are amenable to intervention, whereas others are not.

7. One of the more widely used suicide assessment tools is the SAD PERSONS scale.

8. The SAD PERSONS scale acutely predicts suicidal behaviour.

9. Thorough documentation and communication of details is important to ensure adequate monitoring and the safety of the patient.

10. Having one or more previous suicide attempts is not a strong predictor of suicide risk.

11. Having pervasive thoughts of hopelessness has been identified as a very important risk factor.

12. Interventions should aim to strengthen protective factors such as strong interpersonal relationships.

13. Eliciting suicidal ideation requires a step-wise approach.

14. If there are no thoughts of self-harm, the patient is said to have active suicidal ideation.

15. The primary care physician should not ask further questions to look for behaviour that suggests intent or whether there is a specific plan to carry out a suicide.

16. All persons with clear-cut, active suicidal ideation should be sent to the designated hospital (Institute of Mental Health in the Singapore context) for urgent psychiatric care.

17. The practice of forming no-suicide contracts should be encouraged.

18. A holistic approach should be employed in assessing suicide.

19. All persons who are depressed or suicidal should not be connected to available community resources and crisis helplines.

20. Suicide risk assessment is a complex and challenging process that relies on effective communication, and it is an ongoing process for the depressed patient.

\section{Doctor's particulars:}

Name in full

MCR number

Email address

Specialty:

\section{SUBMISSION INSTRUCTIONS:}

(1) Visit the SMJ website: http://www.smj.org.sg/current-issue and select the appropriate set of questions. (2) Provide your name, email address and MCR number. (3) Select your answers and click "Submit".

RESULTS:

(1) Answers will be published online in the SMJ April 2017 issue. (2) The MCR numbers of successful candidates will be posted online at the SMJ website by 30 March 2017. (3) Passing mark is $60 \%$. No mark will be deducted for incorrect answers. (4) The SMJ editorial office will submit the list of successful candidates to the Singapore Medical Council. (5) One CME point is awarded for successful candidates.

Deadline for submission: (February 2017 SMJ 3B CME programme): 12 noon, 23 March 2017. 